\title{
Estimates of the climate impact of future small-scale supersonic transport aircraft - results from the HISAC EU-project
}

\author{
V. Grewe \\ volker.grewe@dlr.de \\ Deutsches Zentrum für Luft- und Raumfahrt, Institut für Physik der Atmosphäre, Oberpfaffenhofen Wessling \\ Germany
}

\section{Plohr}

Deutsches Zentrum für Luft- und Raumfahrt, Institut für Antriebstechnik Köln, Germany

\section{G. Cerino and M. Di Muzio}

AleniaAeronautica

Naples, Italy

\section{Y. Deremaux, M. Galerneau and P. de Saint Martin \\ Dassault Aviation \\ Paris, France}

\section{T. Chaika}

Sukhoi Civil Aviation

Moscow, Russia

\section{A. Hasselrot and U. Tengzelius \\ FOI, Swedish Defence Research Agency \\ Stockholm, Sweden}

\section{D. Korovkin}

Central Institute of Aviation Motors

Moscow, Russia

\begin{abstract}
The climate impacts of three fleets of supersonic small-scale transport aircraft (S4TA) are simulated. Based on characteristic aircraft parameters, which were developed within the EU-project HISAC, emissions along geographically representative trajectories are calculated and in addition the resulting changes in the atmospheric composition (carbon dioxide, ozone layer, water vapour) and climate (near surface global mean temperature) are deduced. We assume a fleet development with an entry in service in 2015 , a full fleet in 2050 . The results show a temperature increase of $0 \cdot 08 \mathrm{mK}(0 \cdot 07-0 \cdot 10 \mathrm{mK})$ with only small but statistically significant variations between the configurations, leading to a minimum climate impact for a weight optimised and hence lower flying aircraft. A climate impact ratio of $3 \cdot 0 \pm 0 \cdot 4$ between a S4TA and its subsonic counterpart is calculated, which is considerable less than for previous supersonic fleets because of a lower flight altitude, leading to smaller water vapour impacts.
\end{abstract}

\section{NOMENCLATURE}

$E I N O_{x} \quad$ emission index of $\mathrm{NO}_{x}\left(\mathrm{NO}+\mathrm{NO}_{2}\right)$ in $\mathrm{NO}_{2}$ units

$\angle P P \quad$ lean premixed prevapourised

MTOW maximum take-off weight

pax passenger

$p_{3} \quad$ combustor entry pressure

$R F \quad$ radiative forcing

S4TA supersonic small-scale transport aircraft

$\Delta T \quad$ global mean near-surface temperature change

$\Delta T_{X} \quad$ global mean near-surface temperature change for aircraft $X$

$\Delta T_{X}^{r e l} \quad$ relative change in global mean near-surface temperature change for aircraft $X$ relative to a mean aircraft.

$T_{3} \quad$ combustor entry temperature 


\subsection{INTRODUCTION}

Air traffic is a part of human's mobility with an increasing rate in transport volume in the order of 5\% per year from 1992 to $2005^{(1)}$. Climate impact of current air traffic is contributing by $4.9 \%$ to global warming with a $90 \%$-likelihood range of $2-14 \%{ }^{(1)}$. This contribution to climate change is expected to grow further. The business jet sector is, though relatively small compared to passenger transport, currently even increasing at a rate of $8-10 \%$ per year ${ }^{(2)}$. Travel times play an important role, which implies a market for supersonic small-scale passenger aircraft.

Supersonic aircraft fly at a higher cruise level, deep in the stratosphere, which leads to a larger climate impact compared to subsonic aircraft, basically because of the increasing importance of water vapour emissions when increasing the cruise altitude ${ }^{(3,4)}$. The ratio of the climate impact from a supersonic fleet to a respective subsonic fleet depends on the type of aircraft, e.g. cruise altitude, flight pattern, etc. An investigation for a passenger aircraft (250 pax, Mach 2 , cruise level between 54 and $64 \mathrm{kft}$ ) revealed a climate impact ratio of 6 with an uncertainty range of 3-12(5). This study also concluded that the difference between subsonic and supersonic business jets is very likely to be smaller than this factor of 6 , because nowadays subsonic business jets already fly at a higher cruise level than normal passenger aircraft, which decreases the difference in cruise level between these two aircraft types.

Currently no supersonic passenger aircraft is flying routinely, whether small- or large-scale. Within the EU project HISAC, three aircraft families were designed, which were optimised with respect to low weight (family A), long range (family B) and low sonic boom (family C).
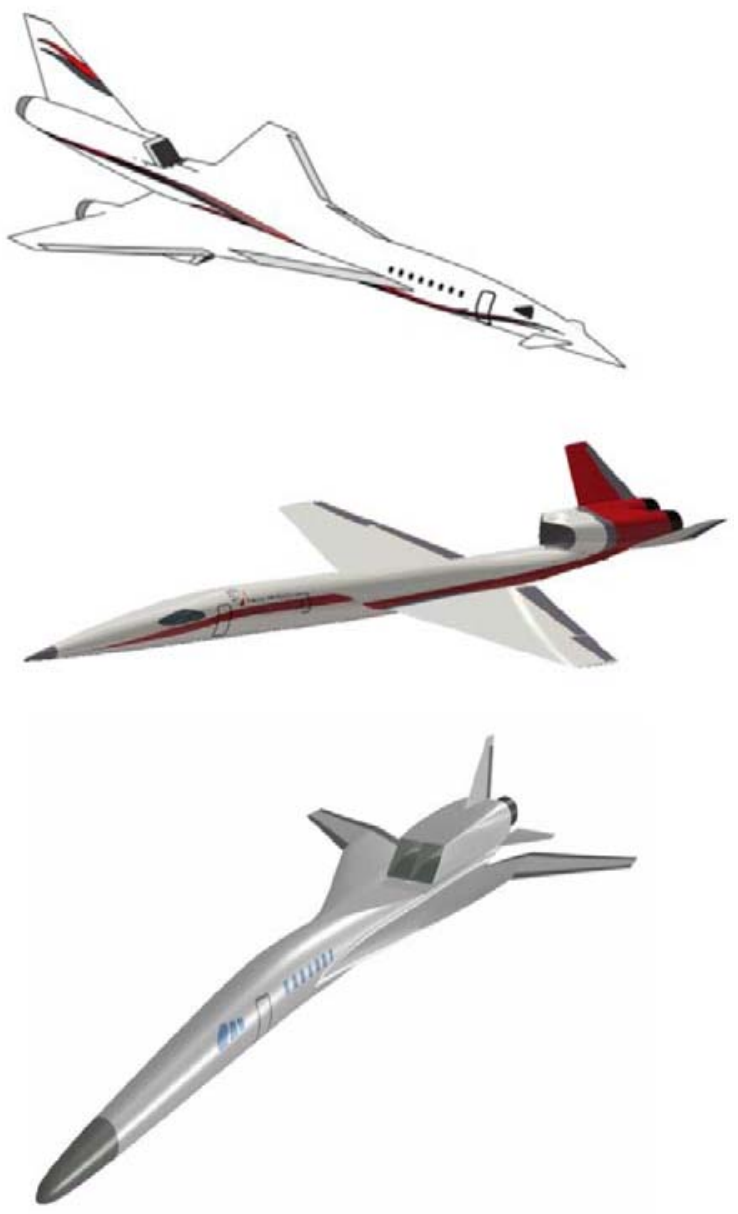

Figure 1. Aircraft configuration A (top), B (mid), and C (bottom).
In this paper, we evaluate the potential climate impact and ozone depletion potential of fleets of these three families. In the next section the aircraft families are described. Section 3 describes the methodology and Section 4 the results.

\subsection{HISAC S4TA AIRCRAFT FAMILIES}

Table 1 shows the common requirements on which the three families are based on. Individual characteristics of the families are given in more detail in Table 2 and Fig. 1. A detailed description of the design process can be found elsewhere (www.hisacproject.com).

The long range aircraft $\mathrm{B}$ and the low boom aircraft $\mathrm{C}$ are considerably larger than configuration $\mathrm{A}$, whereas configuration $\mathrm{B}$ is considerably heavier (MTOW) than the other two configurations, partly due to the longer range, which requires more fuel ( $\sim 5$ tons). A cruise speed of Mach Number (MN) 1.6 is considered.

Table 1

Common requirements

$\begin{array}{lc}\text { Entry into service } & 2015 \\ \text { Reference passengers } & 8 \\ \text { Maximum passengers } & 19 \\ \text { Subsonic cruise } & 0.95 \mathrm{MN} \\ \text { Maximum speed } & 1.6 \mathrm{MN} \\ \text { Maximum altitude } & \text { FL } 410 \\ \text { Maximum range } & 4,000 \mathrm{~nm} \\ \text { Height seating } & 1,785 \mathrm{~mm}\end{array}$

Table 2

Specific configurations

$\begin{array}{lccc}\text { Length (m) } & 36 \cdot 8 & 41 \cdot 6 & 40 \cdot 9 \\ \text { Wing span (m) } & 18 \cdot 5 & 24 \cdot 0 & 19 \cdot 1 \\ \text { MTOW (tons) } & 51 \cdot 1 & 60 \cdot 3 & 53 \cdot 3 \\ \text { Fuel/MTOW (\%) } & 53 & 53 & 51 \\ \text { Max. speed (MN) } & 1 \cdot 6 & 1 \cdot 6 & 1 \cdot 6 \\ L / D & 7 \cdot 00 & 7 \cdot 45 & 7 \cdot 74 \\ \text { Maximum range (nm) } & 4,000 & 5,000 & 4,000 \\ \text { Number of engines } & 3 & 2 & 2 \\ \text { Engine HISAC-ID } & 16 & 24 & 31\end{array}$

\subsection{METHODOLOGY}

\subsection{Overview}

A chain of methodologies and models are employed to estimate the impact of a fleet of S4TA. Specified engine data are used to estimate emission indices for surface conditions by applying correlation methods ${ }^{(6)}$. Aerodynamical aircraft data are employed to calculate the fuel consumption along individual trajectories. Correlation methods and emission indices, specified for surface conditions are then combined to calculate emissions along the flight trajectory, leading to $3 \mathrm{D}$ emission inventories. These are taken as input data for the simplified climate-chemistry model AirClim ${ }^{(5)}$. A parameter variation is performed to investigate the impact of uncertainties in atmospheric processes on the difference in climate response from the three S4TA fleets. The climate responses from $\mathrm{CO}_{2}$, water vapour and ozone are taken into account, which 
represent the main contributors. Impacts from contrails are neglected, because a substitution of subsonic aircraft with supersonics leads to a negligible contrail climate change impact, since the contrail occurrence is shifted from mid latitudes to lower latitudes and lower altitudes to higher altitudes, which gives an almost zero net effect ${ }^{(7)}$.

\subsection{Emissions for surface conditions}

Two combustion chamber concepts are taken into account for the calculation of $\mathrm{NO}_{\mathrm{x}}$ emissions: A conventional (CONV) and a lean premixed prevapourised (LPP) combustion chamber. With these methods the range of possible $\mathrm{NO}_{\mathrm{x}}$ emission indices is fully covered: The conventional combustion chamber is designed with a relatively large volume and represents a long existing technology. The LPP technology has been tested only in test beds, representing a near future option for low $\mathrm{NO}_{\mathrm{x}}$ emission engines.

The methodology of calculating the emission indices has been fully described in Ref. 6 . Hence, only a summary is given here: For each engine a comparable reference engine from the ICAO data base is chosen. The emission indices at some operating points from the reference engine, which are available in the ICAO database, are converted into reference emission indices at the respective operating conditions by applying the DLR-Stöppler correlation method (see also Fig. 1 in Ref. 6). This converts the $\mathrm{EINO}_{\mathrm{x}}$ of the reference engine at the given operating points to the $\mathrm{EINO}_{\mathrm{x}}$ of the HISAC engine at the given operating points. The p3-T3 correlation gives then the emission index over the whole operating range of the regarded engine for surface conditions. Again, this method requires some engine internal data that has to be produced by, e.g., an engine performance programme and type-specific coefficients, which were derived based on emission measurements on a reference combustor.

\subsection{Emissions along the trajectories}

In order to calculate $3 \mathrm{D}$ emission inventories, i.e. emissions along trajectories, two steps are necessary. First, the fuel consumption is calculated along the trajectory. Second, emissions are calculated by the DLR fuel flow method ${ }^{(8)}$, based on the fuel consumption, atmospheric environment (temperature, pressure and humidity) and the emission indices for surface conditions (see Section 3.2), which depend on actual engine variables, like combustor inlet pressure, air fuel ratio, and primary zone temperature. See also Refs 6 and 9 for further details.

The impact on the atmosphere depends on the location of the emission with respect to latitude and height. Therefore, we have chosen four long-range flights, covering the main geographical regions: High latitudes, mid latitudes, tropical low latitudes, and Southern Hemisphere (Table 3). The investigation of the climate impact of S4TA would require an estimate of their flight movements. However, these are available for the US, only ${ }^{(10)}$. An extrapolation to worldwide movements is not feasible and emission inventories for normal passenger flights are not representative. Therefore, we use a simplified approach, by taking a combination of the four trajectories with the weighting 1:2:5:2 as an estimate for a global coverage.

Table 3

\section{City pairs}

$\begin{array}{lcc}\text { Region } & \text { City pair } & \begin{array}{c}\text { Distance } \\ \text { (nm) }\end{array} \\ \text { High latitude } & \text { Quebec - Murmansk } & 3,123 \\ \text { Mid latitude } & \text { Paris - New York } & 3,156 \\ \text { Low latitude } & \text { Bogota - Dakar } & 3,403 \\ \text { Southern } & \text { Florianpolis - Cape Town } & 3,418\end{array}$

Hemisphere

\subsection{Impact on the atmosphere}

The impact on the atmosphere is calculated by applying the AirClim $^{(5)}$ model and climate functions ${ }^{(6)}$, which represent the mean response of the AirClim model.

AirClim is a model which comprises a linearisation of atmospheric processes from the emission to radiative forcing, resulting in an estimate in near surface temperature change, which is presumed to be a reasonable indicator for climate change. The model is designed to be applicable to aircraft technology, i.e. the climate agents $\mathrm{CO}_{2}, \mathrm{H}_{2} \mathrm{O}, \mathrm{CH}_{4}$ and $\mathrm{O}_{3}$ (latter two resulting from $\mathrm{NO}_{\mathrm{x}}$ emissions) and line-shaped contrails are taken into account. AirClim combines a number of pre-calculated atmospheric data with aircraft emission data to obtain the temporal evolution of atmospheric concentration changes, radiative forcing and temperature changes.

A detailed description of AirClim can be found in Ref. 5. The precalculated atmospheric data, which are the essential part of AirClim were derived with detailed climate-chemistry model simulations, in which emission regions with a normalised (= equal for all regions) emission strength (in mass mixing ratios per time) were defined. For each of the idealised emission regions, a climate-chemistry simulation $\left(\mathrm{E} 39 / \mathrm{CA}^{(11)}\right)$ was performed employing normalised emissions of nitrogen oxides and water vapour to obtain their chemical responses, i.e. the simultaneous effects of nitrogen oxides and water vapour on chemical species like ozone and hydroxyl radicals. Then, in a second and third step chemical perturbations and radiative forcings of ozone, methane, and water vapour were calculated applying a state-of-the-art climate model. The results of these simulations represent the atmosphere's response to localised emissions. Any 3D emission field can then be decomposed into contributions from the idealised emission regions, which define a linear combination of response pattern, giving the $3 \mathrm{D}$ atmospheric response pattern. This response pattern resembles in great detail the results of sophisticated climate-chemistry models ${ }^{(5)}$, for larger perturbations as well as small changes in emission pattern, e.g., arising from flight altitude changes ${ }^{(12)}$. Note that this approach does not include a linear chemistry scheme, but a linearisation of the chemical response to a local emission. A detailed validation of the underlying climate-chemistry model can be found in Refs 13 and 11, showing, e.g. the excellent performance with respect to atmospheric water vapour concentrations in the lower stratosphere.

In order to estimate the climate impact of a fleet of S4TA, assumptions on the temporal evolution of the emissions have to be made. Table 4 summarises the main characteristics of the assumed fleet evolution. The results will scale linearly with flight movements. However, the individual times when individual aircraft are delivered and taken into service have an impact on the overall fleet development, which has a non-linear impact on the accumulation of $\mathrm{CO}_{2}$ in the atmosphere. An exponential increase at a $\sim 17 \%$ annual rate is taken into account.

\section{Table 4 \\ Fleet evolution}

$\begin{array}{lc}\text { Entry into Service } & 2,015 \\ \text { Full fleet } & 2,050 \\ \text { Constant fleet size until } & 2,100 \\ \text { Number of aircraft in } 2050 & 250 \\ \text { Flights per aircraft and year } & 100\end{array}$

\subsection{Uncertainty analysis}

The abilities of current climate-chemistry modelling are limited. This investigation focuses on the impact of emissions in the stratosphere on chemistry and climate. Although the underlying model well simulates the evolution of the ozone layer ${ }^{(14)}$ and stratospheric turn around times ${ }^{(13)}$, several uncertainties arise, which limit the accuracy of the results from climate-chemistry modelling. The most important uncertainties for this application are ${ }^{(4)}$ : lifetime of a stratospheric 
water vapour perturbation, strength of ozone depletion due to $\mathrm{NO}_{\mathrm{x}}$ emissions, radiative forcing of a water vapour perturbation and the climate sensitivity of a perturbation of radiative active gases (greenhouse gases).

Estimates of the uncertainty range exist to all of those parameters $^{(4)}$. Multiple simulations with AirClim are performed by parameter variation to investigate the impact of these uncertainties on the results. This leads to a best estimate of the climate impact (near surface temperature change) of a S4TA fleet by the year 2100 and an uncertainty range.

The uncertainties are related to atmospheric processes and are independent from the aircraft configuration. Since the difference in the climate impact of aircraft configurations is in the focus of this investigation, more information is obtained by a parameter variation on the temperature difference. The difference in climate impact between the families is calculated as the relative change with regard to the mean of all three fleets. For a parameter setting $p$, the absolute temperature change $\Delta T_{X}(p)$ for a family $X$ is calculated and the relative change $\Delta T_{X}^{\text {rel }}(p)$ determined:

$$
\Delta T_{X}^{r e l}(p)=\frac{\Delta T_{X}(p)}{\frac{1}{3}\left(\Delta T_{A}(p)+\Delta T_{B}(p)+\Delta T_{C}(p)\right)} \times 100 \%
$$

Parameter ranges are taken as minimum-maximum ranges according to Ref. 5: The parameters vary between $\pm 10 \%$ to $\pm 50 \%$.

With this approach statistically significant changes can be detected, although the uncertainty of the mean values might be large.

\subsection{ATMOSPHERIC IMPACT OF A S4TA FLEET}

In this section, we present the results with regard to emissions, changes in the atmospheric concentration, and respective changes in climate for the three regarded fleets of S4TA families.

\subsection{Emissions}

The fuel consumptions of the three fleets of configuration A, B and $\mathrm{C}$ are shown in Fig. 2 (left). They resemble the differences in aircraft design, i.e., weight, $L / D$, etc. However, the general shapes of the profiles are similar. Mean values are given in Table 5. Taking into account 250 aircraft with 100 flights per year each, this sums up to $0.4 \mathrm{Tg}$ fuel per year (Table 5), clearly less than for large passenger aircraft considered in previous programs, e.g. SCENIC ${ }^{(4,5)}: 62 \mathrm{Tg}$ per year and IPCC/HSRP ${ }^{(3,16)}$ : $137 \mathrm{Tg}$ per year. Two peaks are clearly visible around $100 \mathrm{hPa}$ and $350 \mathrm{hPa}$, which reflect supersonic cruise and transonic acceleration.

The $\mathrm{NO}_{\mathrm{x}}$ emissions peak at the same altitude as the fuel consumption (Figure 2, mid). The $\mathrm{NO}_{\mathrm{x}}$ emission index is estimated to be between $10 \cdot 5$ and $12 \cdot 0 \mathrm{~g}$.

$\mathrm{NO}_{2}$ per kilogram fuel. Earlier studies (HSRP, IPCC, and SCENIC) have estimated a theoretical possible emission index of around $5 \mathrm{~g} / \mathrm{kg}$, whereas here, the results are based on expert knowledge from actual measurements of emissions in a test bed $^{(6)}$. The conventional combustion chamber as characterised in the HISAC project is a 'worst case scenario', based on a large volume of the combustion chamber, representative for Concorde's technology. Combustion chamber technologies were not specifically addressed in the HISAC project.

Table 5

Emissions

\section{Configu- Flight ration altitude (kfeet)}

$\begin{array}{cc}\text { A } & 50 \cdot 6 \\ \text { B } & 52 \cdot 6 \\ \text { C } & 54 \cdot 0 \\ \text { SCENIC } & 54-64\end{array}$

$\begin{array}{ccc} & \begin{array}{c}\text { Mean fuel } \\ \text { consumption }\end{array} & \begin{array}{c}\text { EINO }_{\mathbf{x}} \\ \text { (LPP) } \\ \left(\mathbf{g}\left(\mathbf{N O} \mathbf{O}_{2}\right)\right. \\ \mathbf{/ k g ( f u e l )})\end{array} \\ \text { Flight (t) } & \text { Annual (Tg) } \\ 15.84 & 0.396 & 11.8 \\ 15.89 & 0.397 & 11.9 \\ 17.76 & 0.44 & 10.6 \\ - & 62.0 & 4.6\end{array}$

\subsection{Temporal evolution and carbon dioxide}

For the evaluation of the climate impact, it is essential to take into account long-term developments, because $\mathrm{CO}_{2}$, ozone and water vapour have very different impacts on different timescales. Instantaneous changes may be small for $\mathrm{CO}_{2}$ compared to ozone.

However, the atmospheric residence time of a $\mathrm{CO}_{2}$ perturbation is considerably larger. To take this into account, an emission evolution from 1940 to 2100 has been developed on the basis of SCENIC ${ }^{(4)}$, which takes into account a first use of a supersonic configuration in 2015 and a full fleet in 2050. The fleet is kept constant between 2050 and 2100 (see also Table 4). Figure 3 shows the temporal development of the $\mathrm{CO}_{2}$ emissions from the whole subsonic SCENIC fleet (blue), the SCENIC mixed fleet (red) and the HISAC fleet (green) (values before 1990 are omitted in the Figure for illustration purpose).
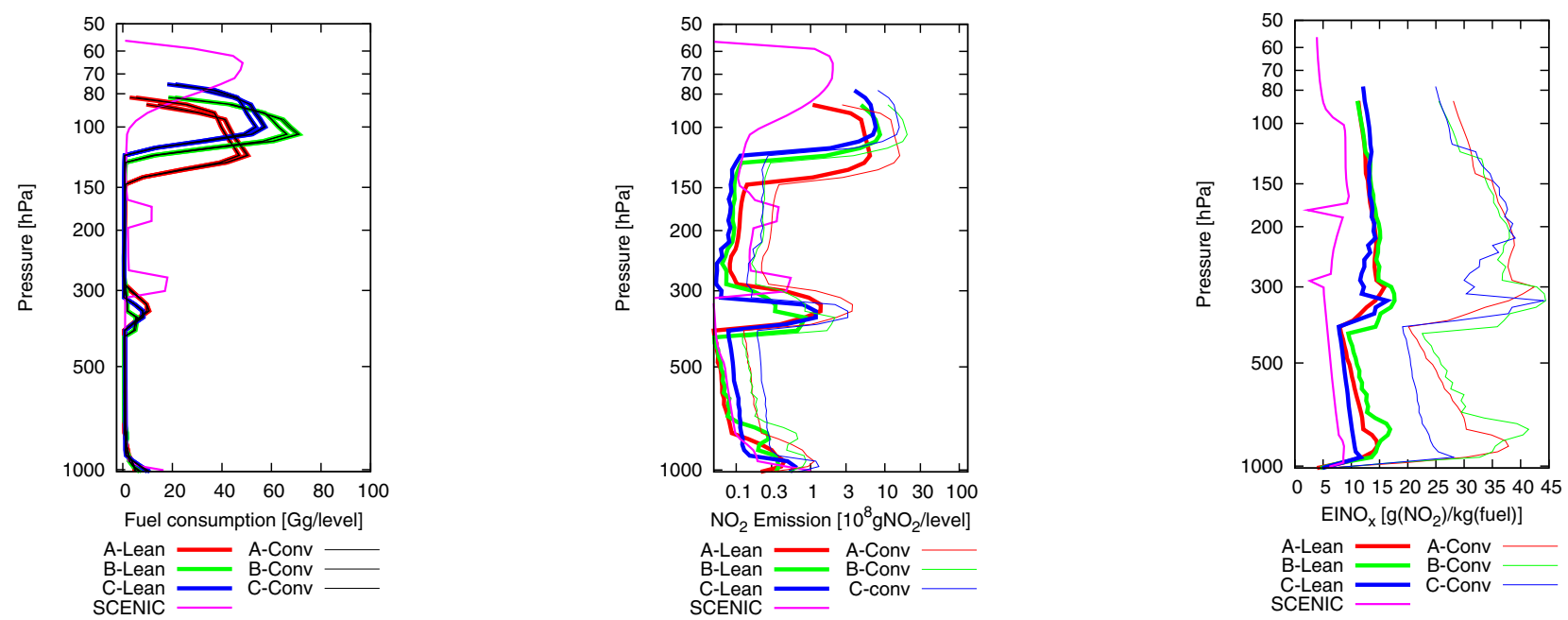

Figure 2. Globally and annual mean fuel consumption (left), $\mathrm{NO}_{2}$ emissions (mid) and $\mathrm{NO}_{x}$ emission index (right) for a fleet of S4TA: A (red), B (green), and C (blue). SCENIC data are added as a reference, scaled to the mean S4TA fuel consumption. 

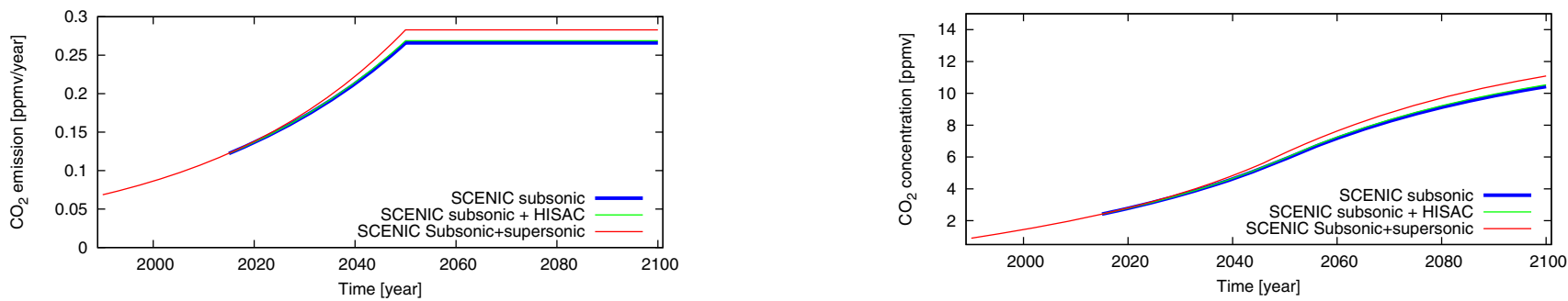

Figure 3. Evolution of $\mathrm{CO}_{2}$ air traffic emissions (left) and respective concentrations (right). Three scenarios are shown: Subsonic only (blue), subsonic plus a mean HISAC supersonic fleet (green) and subsonic plus the SCENIC supersonic fleet (red).
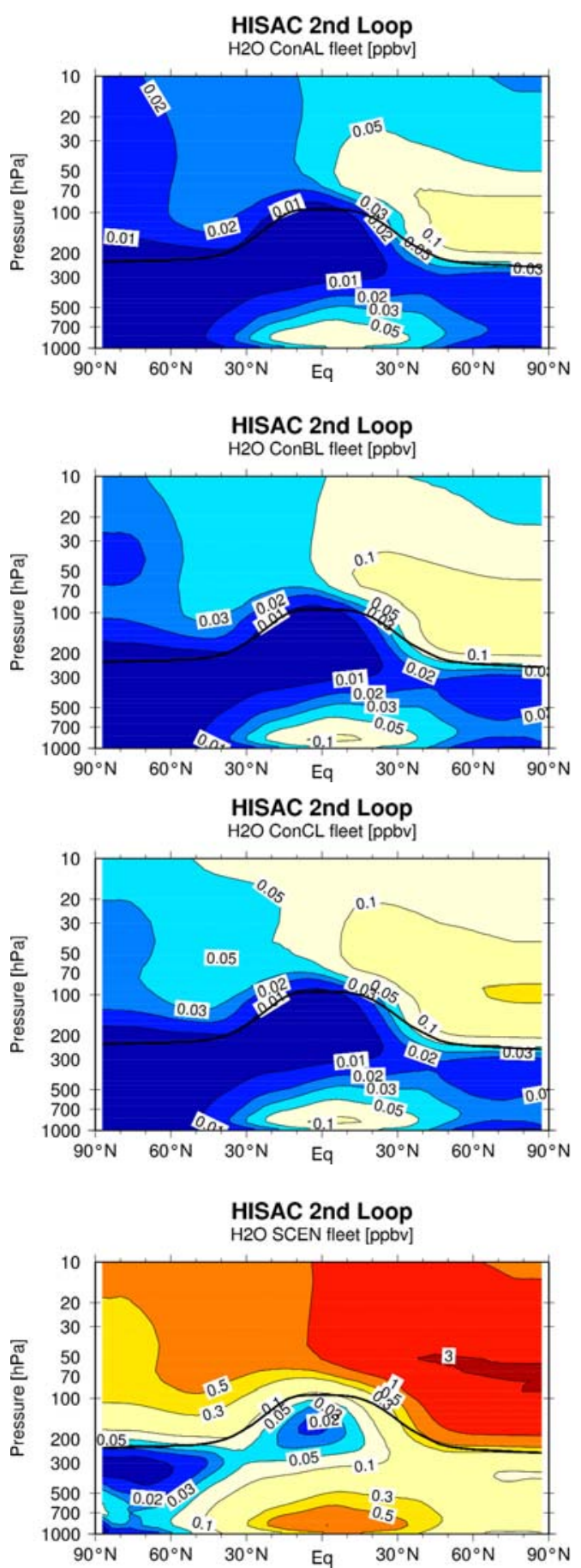
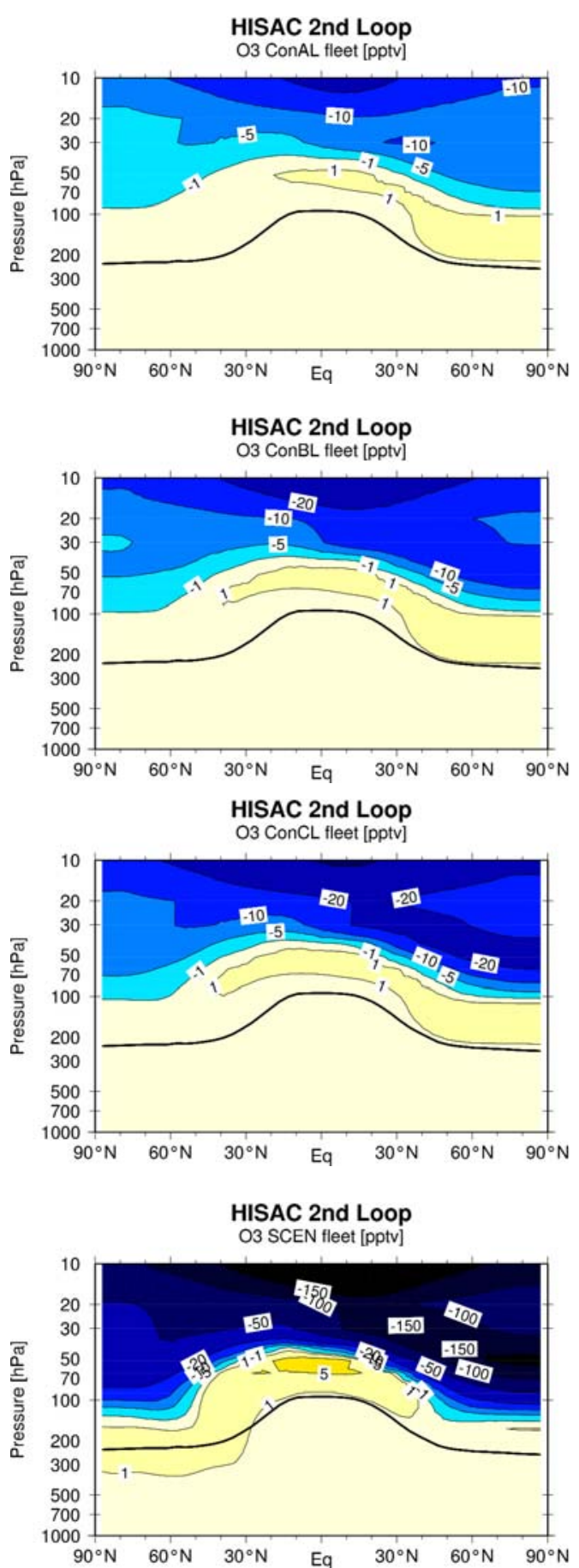

Figure 4. Zonal and annual mean water vapour changes (left) in (ppbv) and ozone changes (right) in (pptv) induced by 2050 emissions from HISAC configurations A ( $1^{\text {st }}$ row $), B\left(2^{\text {nd }}\right.$ row $), C\left(3^{\text {rd }}\right.$ row) and SCENIC (bottom) aircraft. SCENIC emission data are scaled to the same fuel consumption as the mean HISAC fleet in order to compare the relative importance of non- $\mathrm{CO}_{2}$ impacts. The black line indicates the tropopause. 

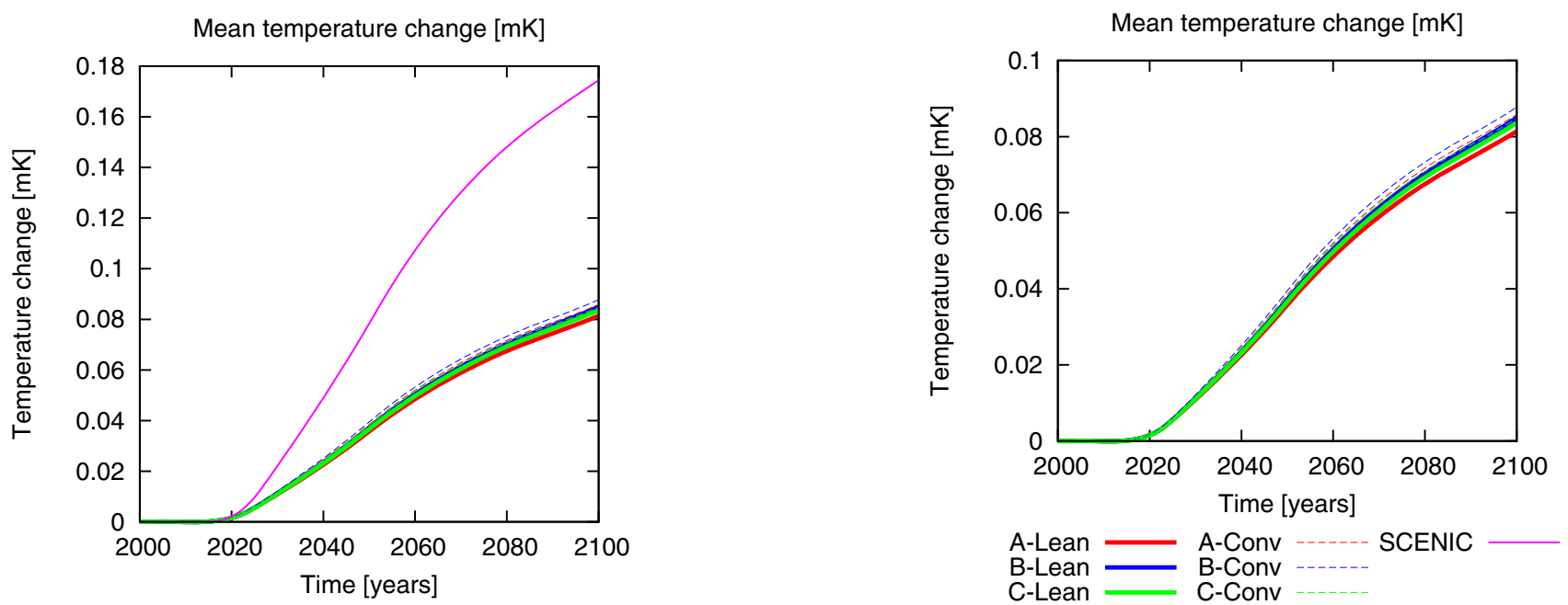

Figure 5. Temporal development of the temperature response [mK] of supersonic HISAC S4TA fleets. Individual configurations (A, B, and C) are indicated by colour. Solid lines refer to LPP technology, whereas dashed refer to conventional combustion chamber (see text for details). SCENIC results (highest solid line) are scaled to give the same fuel consumption as the $\mathrm{HISAC}$ fleet in order to provide an estimate for non-CO ${ }_{2}$ effects (left). Right: as top but for a smaller temperature range.

The contribution of the S4TA fleet to the estimated total air traffic fuel consumption is small $(0 \cdot 06 \%)$ and hence hardly visible in Fig. 3. The $\mathrm{CO}_{2}$ concentration due to air traffic, as calculated with AirClim, is increasing even after the emissions are kept constant (bottom), because the lifetimes of $\mathrm{CO}_{2}$ perturbations are in the order of decades.

\subsection{Chemical changes and ozone depletion}

Changes in the atmospheric composition are calculated with the simplified climate-chemistry model AirClim, which has been developed and validated for supersonic transport applications ${ }^{(5)}$. Figure 4 shows the impact of the HISAC fleets and the scaled SCENIC fleet on water vapour (left) and ozone (right) for 2050, i.e. at the time where the full fleet is established. Roughly an increase in water vapour in the order of $0.1 \mathrm{ppbv}$ and in the Northern Hemisphere mid and high latitudes at a round $100 \mathrm{hPa}(\sim 18 \mathrm{~km})$ and a decrease in ozone of around $20 \mathrm{pptv}$ in the tropics at around $10 \mathrm{hPa}$ $(30 \mathrm{~km})$ and higher latitudes at around $50 \mathrm{hPa}(\sim 22 \mathrm{~km})$ is simulated. The global mean ozone depletion is in the order of $0.0005 \%$ relative to the background ozone concentration. The lower flight altitude of the HISAC aircraft compared to the SCENIC fleet (bottom, left) leads to smaller accumulation of water vapour in the lower stratosphere by a factor of ten. Configuration $\mathrm{C}$ is characterised by both, higher fuel consumption and a high cruise altitude, which leads to a slightly larger water vapour accumulation compared to configurations $\mathrm{A}$ and $\mathrm{B}$. Largest ozone depletion among the three configurations is caused by aircraft $\mathrm{C}$ again due to the higher altitude and larger fuel consumption, which outweighs the low emission index for $\mathrm{NO}_{\mathrm{x}}$ of configuration $\mathrm{C}$ (Table 5). Configuration $\mathrm{A}$ causes the lowest ozone depletion of around 25pptv in the tropical stratosphere.

A factor of two is achieved by LPP technology in reducing the ozone depletion, i.e. from 50 to $25 \mathrm{pptv}$, roughly (not shown).

\subsection{Climate change}

Emissions of a potential S4TA fleet change the composition of radiatively active greenhouse gases and hence affect climate. Figure 5 shows the temporal evolution of the climate impact caused by a supersonic fleet for the different configurations and for comparison for the SCENIC fleet, scaled to the same fuel consumption. The temperature change by 2100 is calculated to be around $0.08 \mathrm{mK}$.
A parameter variation leads to an uncertainty range of $0.07 \mathrm{mK}$ to $0 \cdot 10 \mathrm{mK}$. Around $50 \%$ of the climate impact arises from $\mathrm{CO}_{2}$ emissions, $20 \%$ from water vapour and $30 \%$ from ozone. Here we neglect impacts from contrails, because a substitution of subsonic aircraft with supersonic leads to a negligible contrail climate change impact, since the contrail occurrence is shifted from mid latitudes to lower latitudes and lower altitudes to higher altitudes, which gives an almost zero net effect ${ }^{(7)}$. The climate impact of the scaled SCENIC fleet is double as large. The difference to the HISAC fleets occur solely from non- $\mathrm{CO}_{2}$ effects, namely water vapour, which stronger accumulates, when emitted at higher altitudes (see also below).

\subsection{Minimal impact}

The difference between the three S4TA fleets with respect to the climate impact is small and considerably smaller than the uncertainty in the absolute temperature change. The uncertainty analysis is based on a parameter variation. By applying this parameter variation for the difference in the temperature change (Equation (1)) rather than the absolute temperature change, even small differences have the chance to become statistically significant (see also Section 3.5).

Figure 6 shows the intercomparison of the climate impact of configuration $\mathrm{A}, \mathrm{B}$, and $\mathrm{C}$. The applied metric is the temperature change in 2100 of either configuration compared to the mean value of all three configurations. For a conventional combustion chamber (Conv), configuration $\mathrm{A}$ and $\mathrm{C}$ show significantly smaller temperature change than configuration B. For LPP technology (LPP), configuration $\mathrm{A}$ has the lowest overall climate impact.

\subsection{DISCUSSION}

\subsection{Comparison to supersonic programs}

An important conclusion of this investigation is the large effect of the cruise altitude on the impact on climate due to non- $\mathrm{CO}_{2}$ contributions, which confirms earlier findings ${ }^{(3,4)}$.

Table 6 gives an overview on previous research programs on supersonic transport over the last ten years. Differences occur in the size of the aircraft, ranging from small aircraft (8 to 10pax, NASA 


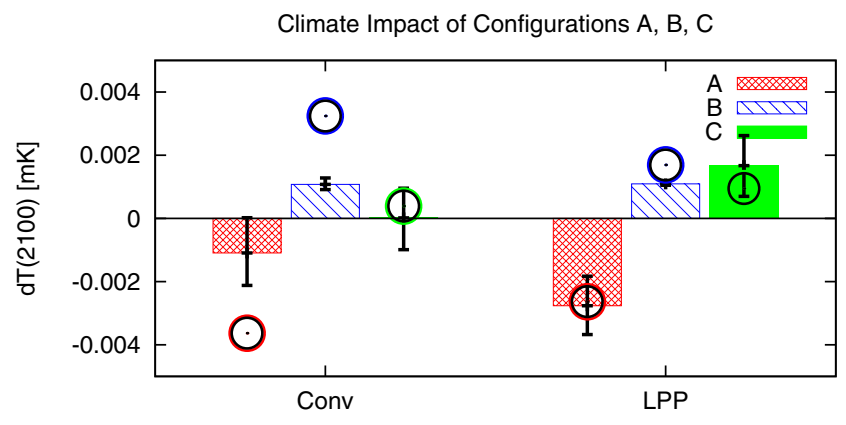

Figure 6. Climate impact of configurations $A, B$, and $C$ in comparison to mean climate impact of all three configurations. The error bars indicate an uncertainty based on atmospheric processes. The error estimation is conservative. Circles indicate the results based on climate functions ${ }^{(6)}$, which are discussed in Section 5.2.

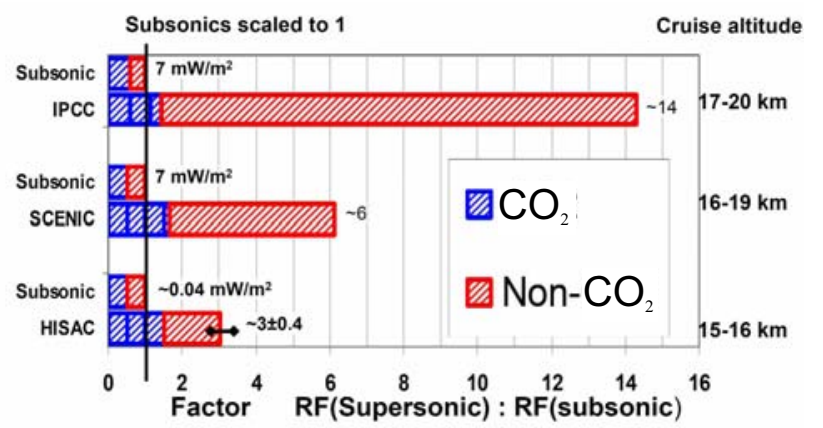

Figure 7. Intercomparison of subsonic and supersonic aircraft configurations from various research programs (IPCC, SCENIC, HISAC) with respect to radiative forcing for the year 2050 . The respective subsonic aircraft is scaled to one for each program (the unscaled RF values are given for the subsonic aircraft). The RF from a supersonic fleet is given as a multiple of the respective subsonic fleet. For HISAC no estimates for subsonic counterparts are available, therefore an estimate is given, which is based on two assumptions (see text for details).

ratio between sub- and supersonic transport. This ratio between suband supersonic transport is shown in Fig. 7 for the fleets from IPCC, SCENIC and HISAC. The respective subsonic fleet is scaled to one. The climate impact in terms of radiative forcing is calculated as the ratio of the climate impact of the supersonic fleet and that of the respective subsonic fleet. The intercomparison is based on carbon dioxide, water vapour, and ozone perturbations. The supersonic to subsonic ratio is 14 and 6 for the IPCC and SCENIC fleets, respectively (Figure 7). For the HISAC subsonic fleet, we assumed that (1) the ratio of $\mathrm{CO}_{2}$ to non- $\mathrm{CO}_{2}$ effects is the same as for the SCENIC subsonic counterpart and (2) the ratio between the fuel consumption of the super- to the subsonic aircraft is around three, based on IPCC, SCENIC and expert knowledge. A $15 \%$ uncertainty range is taken into account for these two assumptions as well as for the non- $\mathrm{CO}_{2}$ effects of the HISAC fleet. A parameter variation leads to a best estimate of a factor of 3 and an uncertainty range of $\pm 0 \cdot 4$. The $15 \%$ uncertainty range implies a factor for the fuel consumption of 2.55 to 3.45 between a S4TA and a subsonic counterpart. If this factor is reduced to 2, e.g. for long range missions, the overall climate impact factor is reduced to $2 \cdot 0 \pm 0 \cdot 2$.

Clearly, the impact of non- $\mathrm{CO}_{2}$ effects is increasing with increasing altitude. At cruise altitudes between 17 and $20 \mathrm{~km}$ the non- $\mathrm{CO}_{2}$ effects are dominating, whereas at cruise flight 15 to $16 \mathrm{~km}$ the non- $\mathrm{CO}_{2}$ effects on climate are comparable to the $\mathrm{CO}_{2}$ impact.

Table 6

Overview on supersonic projects

\begin{tabular}{|c|c|c|c|c|c|c|}
\hline & $\operatorname{HSRP}^{(16)}$ & IPCC $^{(3)}$ & SCENIC $^{(4)}$ & $\mathbf{N A S A}^{(10)}$ & $\mathbf{N A S A}^{(15)}$ & HISAC \\
\hline Year of publication & 1999 & 1999 & 2007 & 2002 & 2004 & This issue \\
\hline $\mathrm{A} / \mathrm{c}$ concept & Boeing & Boeing & Airbus & Boeing & Boeing & $\begin{array}{c}\text { Dassault, } \\
\text { Alenia, Sukhoi }\end{array}$ \\
\hline Time of full fleet & 2015 & 2050 & 2050 & 2015 & $2015-2020$ & 2050 \\
\hline Mean cruise altitude $(\mathrm{km})$ & $18-21$ & $17-20$ & $16-19$ & $15,17,19$ & $14,16,18$ & $15-16$ \\
\hline Number of aircraft & 500 & 1000 & 500 & 500 & - & 250 \\
\hline Passenger & $\sim 300$ & 309 & 250 & 10 & $12-13$ & 8 \\
\hline \multicolumn{7}{|l|}{ Speed } \\
\hline (Mach) & $2 \cdot 4$ & $2 \cdot 4$ & $2 \cdot 0$ & $<<2 \cdot 4$ & $1 \cdot 6-2$ & $1 \cdot 6-1 \cdot 8$ \\
\hline Fuel consumption & 82 & 137 & 62 & $1-4$ & $1-4$ & $0 \cdot 4$ \\
\hline
\end{tabular}

$(109 \mathrm{~kg} / \mathrm{a})$

Climate impact (RF) Not calculated 
Since this is likely to be similar for a subsonic counterpart (see above), the ratio of the climate impact of super- to subsonic aircraft approximately scales with the ratio in the fuel consumption.

\subsection{Options for future aircraft design}

The evaluation of the climate impact as performed in this study requires calculations of trajectories and emissions along trajectories, which then serve as an input to the simplified climate-chemistry model AirClim. This approach is hardly applicable in aircraft design, since it is too resource demanding. Therefore, a simplification was suggested $^{(6)}$, which directly relates, for given engines and combustion chambers, aircraft/engine parameters (cruise altitude, Mach Number, fuel flow, and total fuel consumption) for cruise conditions to near surface temperature changes in 2100 . Hence the climate functions evaluate the climate impact at cruise conditions for a global mean atmosphere. The results of these climate functions are included as circles in Fig. 6. It shows that they represent the main features obtained with the more detailed AirClim model, i.e. configuration $\mathrm{A}$ has the lowest climate impact and configurations $\mathrm{B}$ and $\mathrm{C}$ have a similar impact for the LPP technology. However for the conventional combustion chamber the results of the climate functions are overestimated for configuration $\mathrm{B}$ and give lower results for configuration A compared to AirClim. This confirms the recommendations on the use of the climate functions ${ }^{(6)}$ as an indicator for tendencies rather than for estimates of the absolute climate impact.

\subsection{CONCLUSION}

The climate impacts of three families of supersonic small-scale transport aircraft (S4TA) were studied. The aircraft were designed with respect to weight minimisation (A), range maximisation (B) and sonic boom minimisation (C). The methodology is based on geographically representative flight trajectories on which emissions were calculated for two different combustion chambers. The results show:

- A similar total climate impact for all configurations of $0.08 \mathrm{mK}$ $(0.07$ to $0 \cdot 1 \mathrm{mK})$ in 2100 and a small reduction of the ozone layer of around $0.0005 \%$.

- A slightly, but statistical significantly smaller climate impact for configuration A, because of a slightly lower flight altitude.

- A ratio of $3 \pm 0.4$ in the climate impact between a S4TA and a subsonic counterpart.

- A confirmation of applicability and previously estimated limits of more simplified approaches (climate functions).

Previous studies on the impact of a fleet of S4TA concentrated on the effect on the ozone layer, suggesting only a little impact on stratospheric ozone for cruise altitude between 13 and $15 \mathrm{~km}^{(17)}$ and are expected to be quite small for a fleet of $\mathrm{S} \mathrm{TA}^{(10)}$. But those studies did not estimate a climate impact.

For future investigations it is recommended to estimate global movements of business jets to reduce uncertainties arising from assumed flight pattern. Although it is not expected that contrails play a dominant role in the climate impact caused by a substitution of subsonic by supersonic small-scale aircraft, it would be helpful to confirm that the findings for large passenger aircraft ${ }^{(7)}$ are applicable to S4TA fleets.

\section{ACKNOWLEDGEMENT}

This investigation was funded by the EU-Integrated Project HISAC. We like to thank Klaus-Dirk Gottschaldt, DLR for internal review.

\section{REFERENCES}

1. Lee, D.S., Fahey, D.W., Forster, P.M., Newton, P.J., Wit, R.C.N., Lim, L.L., Owen, B. and Sausen, R. Aviation and global climate change in the 21st century, Atmos Environ, 2009.

2. Communication from the Commission, An agenda for sustainable future in general and business aviation, $\operatorname{COM}(2007), 869$, Commission of the European communities, Brussels, Belgium, 11 January 2008.

3 IPCC: Special Report on Aviation and the Global Atmosphere, in: Intergovernmental Panel on Climate Change, edited by: PENNER, J.E., Lister, D.H., Griggs, D.J., DoKken, D.J. and MCFArland, M., Cambridge University Press, New York, NY, USA, 1999.

4. Grewe, V., Stenke, A., Ponater, M., Sausen, R., Pitari, G., Iachetti, D., Rogers, H., Dessens, O., Pyle, J., Isaksen, I., Gulstad, L., Søvde, O.A., Marizy, C. and Pascuillo, E. Climate impact of supersonic air traffic: an approach to optimize a potential future supersonic fleet Results from the EU-project SCENIC, Atmos Chem Phys, 2007, 7, pp 5129-5145.

5. Grewe, V. and Stenke, A. AirClim: an efficient climate impact assessment tool, Atmos Chem Phys, 2008, 8, pp 4621-4639.

6. Grewe, V., Stenke, A., Plohr, M. and Korovkin, V. Climate functions for the use in multi-disciplinary optimisation in the pre-design of supersonic business jets. This paper is due to be published in the May 2010, 114, (1153), edition of Aeronaut $J$.

7. Stenke, A., Grewe, V. and Pechtl, S. Do supersonic aircraft avoid contrails? Atmos Chem Phys, 2008, 8, pp 955-967.

8. Döpelheuer, A. and Lecht, M. Influence of Engine Performance on Emission Characteristics, RTO MP-14, paper 20, pages 20-1 to 20-12, ISBN 92-837-0009-0, Lissabon, 1999.

9. Hasselrot A, Comsim-Platform - an Object-Oriented Basis for Computing Aircraft Performance and Flight Trajectories, FOI-R-1846SE, ISSN 1650-1942 2007, 2007.

10. Baughcum, S., First Order Ozone Impact of a Fleet of Supersonic Business Jets (SSBJs), NASA-Report, NASA/CR-2002-211898, ARL-CR-0507, September 2002.

11. Stenke, A., Dameris, M. and Garny, H., Grewe, V. Implications of Lagrangian transport for coupled chemistry-climate simulations, Atmos Chem Phy, 2009, 9, 5489-5504.

12. Fichter, C. Climate Impact of Air Traffic Emissions in Dependency of the Emission Location and Altitude, PhD thesis, Manchester Metropolitan University, ISSN 1434-8454, ISRN DLR-FB-2009-22, Köln, pp 151, 2009.

13. Stenke, A, Grewe, V. and Ponater, M. Lagrangian transport of water vapor and cloud water in the ECHAM4 GCM and its impact on the cold bias, Clim Dyn, 2008, 31, pp 491-506, 10.1007/s00382-007-0347-5.

14. Dameris, M., Matthes S., Deckert, R., Grewe, V. and Ponater, M. Solar cycle effect delays onset of ozone recovery, Geophys Res Lett, 33, L03806, doi:10.1029/2005GL024741, 2006.

15. Dutta, M., Patten, K. and Wuebbles, D. Parametric Analyses of Potential Effects on Stratospheric and Tropospheric Ozone Chemistry by a Fleet of Supersonic Business Jets Projected in a 2020 Atmosphere, NASA-Report, NASA/CR_2004-213306, October 2004.

16. Kawa, S.R., Anderson, J.G., Baughcum, S.L., Brock, C.A., Brune, W.H., Cohen, R.C., Kinnison, D.E., Newman, P.A., Rodriguez, J.M., Stolarski, R.S., Waugh, D. and Wofsy, S.C: Assessment of the Effects of High-Speed Aircraft in the Stratosphere: 1998, NASA Technical Report TP-1999-20923, 1999.

17. Baughcum, S.L., Plumb, I.C. and Vohralik, P.F. Stratospheric ozone sensitivity to aircraft cruise altitudes and $\mathrm{NO}_{\mathrm{x}}$ emissions, in: Aviation, Atmosphere, and Climate (AAC), Proceedings of a European Conference, Friedrichshafen, Germany, pp 145-150, 2003. 